\title{
Mortality, risk factors and causes of death in Swedish patients with open tibial fractures - a nationwide study of 3, 777 patients
}

Ulrika Tampe* ${ }^{*}$, Lukas W. Widmer, Rüdiger J. Weiss and Karl-Åke Jansson

\begin{abstract}
Background: Open tibial fractures are serious, complicated injuries. Previous studies suggested an increased risk of death, however, this has not been studied in large population-based settings. We aimed to analyze mortality including causes of death in all patients with open tibial fractures in Sweden. Moreover, we wanted to compare mortality rates with the Swedish population and determine whether treatment-related or demographic variables were independently associated with death.

Method: We searched the Swedish National Hospital Discharge Register for all patients with open tibial fracture between 1998 and 2010. We collected the following variables: age, gender, length of stay, mechanism of injury and treatment rendered. We then cross-referenced the Swedish Cause of Death Register to determine the cause of death, if applicable. We compared mortality in the study population with population-based mortality data from Statistics Sweden and determined whether variables were independently associated with death using regression analysis.

Results: Of the 3777 open tibial fractures, 425 (11.3\%) patients died. The most common causes of death for elderly patients were cardiovascular and respiratory disease. Patients aged 15-39 years succumbed to external causes (accidents, suicides or poisoning). Increasing age (OR 25.7 (95\% Cl 11.8-64.8) $p<0.001$ ), length of hospital stay (HR 1.01, (95\% Cl 1.01-1.02,) $p<0.001)$, limb amputation (OR 4.8 (95\% Cl 1.86-11.1) $p<0.001$ ) and cause of the accident were independently associated with an increased mortality.

Conclusion: Patients with open tibial fractures have an increased risk of death compared with the general population in all age- and gender-groups. External causes of death are over-represented and indicate a subgroup with a risky behaviour among younger males. Elderly patients have an increased risk of dying comparable to hip fracture patients. They are at risk for cardiovascular and respiratory failure and should be treated with urgency, emphasizing the need for specialized geriatric trauma units.
\end{abstract}

Keywords: Causes of death, Epidemiology, Mortality, Open fracture, Tibial fracture

\footnotetext{
* Correspondence: ulrika.tampe@gmail.com

Department of Molecular Medicine and Surgery, Section of Orthopaedics and Sports Medicine, Karolinska Institutet at Karolinska University Hospital, Stockholm, Sweden
}

(c) The Author(s). 2018 Open Access This article is distributed under the terms of the Creative Commons Attribution 4.0 International License (http://creativecommons.org/licenses/by/4.0/), which permits unrestricted use, distribution, and reproduction in any medium, provided you give appropriate credit to the original author(s) and the source, provide a link to the Creative Commons license, and indicate if changes were made. The Creative Commons Public Domain Dedication waiver (http://creativecommons.org/publicdomain/zero/1.0/) applies to the data made available in this article, unless otherwise stated. 


\section{Background}

Open tibial fractures are serious injuries, which endanger both life and limb. The incidence in Northern Europe is between 2.3 and 3.4 per 100,000 person-years [1-3], and consists of a unimodal age distribution for males, whereas women have a more even age distribution. In fact, previous work identified the most common mechanisms of injury as motor vehicle accidents (43\%), most commonly seen in males, age 15-50 years, and falls from a standing-height (21\%), which are most commonly seen in females [2].

Treatment of open tibial fractures is difficult and fraught with complications. Problems such as osteomyelitis, non-union, mal-union, compartment syndrome and amputation contribute to an increase in healthcare costs (resource utilization) as well as a decrease in patient quality of life [4-7]. In fact, the amputation rate is reported to be $3.6 \%$ in a study involving adult Swedish patients [2]. However, in trauma centres dealing with a larger proportion of high-energy injuries, the amputation rate is much higher, about $25 \%[8,9]$.

In contrast to the well-studied mortality rate after hip fractures $[10,11]$ few studies report the risk of death after open tibial fractures. It is possible that high complication rates translate to an increase in the risk of death. In fact, previous studies involving small populations of elderly patients demonstrated relatively high mortality after open tibial fractures $[12,13]$. Other studies involving larger patient populations focus on closed as well as open fractures $[14,15]$. However, neither provides a suitable population-based assessment of the risk of death following treatment for open tibial fracture.

As such, there are no population-based reports documenting short- and long-term mortality rates in patients with open tibial fractures. With this in mind, we aimed to analyse mortality rates, causes of death and risk factors for death in the Swedish population, with data from a nationwide inpatient register. In doing so, we describe the mortality after open tibial fracture in the Swedish population, compare the mortality rates with those in the general Swedish population, and determine whether treatment-related or demographic variables were independently associated with death.

\section{Methods}

\section{Source of data}

We obtained data from the Swedish National Hospital Discharge Register (SNHDR), where 98\% of all hospital admissions in Sweden are covered [16]. The study period was 1998-2010. All Swedish individuals can be identified through a 10-digit national registration number and which allows epidemiological studies on a nationwide basis. Data on diagnosis, surgical procedure codes, and demographic data for each hospital admission in Sweden are available. Diagnoses are coded according to the International Classification of Diseases (ICD). We extracted data from the Register on all hospital admissions and re-admissions of patients ( $\geq 15$ years of age) with the following diagnoses: open fractures of the proximal tibia (S82.11), tibial shaft (S82.21), and distal tibia (S82.31). No exclusions were made.

Mechanism of injury was collected from ICD E-codes and divided into categories: fall from standing height, fall from height, car accidents, transport accidents with unprotected road users (bicycle accidents, motor bike accidents, horse riders, and pedestrians hit by motor vehicles), self-destructive injuries and miscellaneous. Unprotected road users were gathered in one group as there were very few individuals in the sub-groups.

We cross-referenced data from the Swedish National Hospital Discharge Register to the Swedish Cause of Death Register [17, 18]. Dates of death and causes of death for patients from this cohort that died during the study period were extracted. Causes of death were coded according to the International Classification of Diseases (ICD 10) and grouped according to the European shortlist for causes of death [19]. According to this list, causes of death are grouped as diseases of the respiratory, circulatory, digestive, nervous and musculoskeletal system as well as malignant neoplasms, mental and behavioural disorders, endocrine and metabolic diseases, external, unknown and unspecified causes, and miscellaneous. External causes were further divided into transport accidents, accidental falls, accidental poisoning, suicide and intentional self-harm, homicide and assault, drowning accidents and events of undetermined intent.

Patients were grouped as young (15-39 years), middle-aged (40-64 years) and old ( $\geq 65$ years). Males aged 15-60 years as a relatively large group was thoroughly investigated. We hypothesized that they would be more subjected to external causes and violent deaths, as shown in previous studies [20,21].

The primary outcome variable was early mortality, defined as death within 90 days after injury. Furthermore, secondary outcomes were late mortality, defined as death between 90 days and 2 years, total mortality during the study period, length of stay (LOS), standard mortality ratios (SMR) and variables associated with death.

\section{Statistics}

Logistic regression analysis was used to assess factors associated with death within 90 days, as prevalence of early death was not time-homogenous. Cox regression analysis was used for the correlative analysis from 
90 days and beyond. We hypothesized that by doing this, we would estimate the most critical external causes directly associated with the earlier deaths. On the other hand, we would also analyse other long term factors that would influence the risk for a later death. Odds ratios (ORs), hazard ratios (HRs) and the associated $95 \%$ confidence intervals $(\mathrm{CI})$ are presented. The crude results were adjusted for age, gender, mechanism of injury, occurrence of amputation, and length of stay.

The standardized mortality ratio (SMR) is a ratio between observed number of deaths in a study population and the number of expected deaths in the general population, stratified by age and gender. SMR was calculated comparing mortality in the study population with data from Statistics Sweden [22]. The Mid-p exact test was used to calculate confidence intervals for SMR.

The Kaplan-Meier survival function was plotted for different age and gender groups, compared to data from the general population, matched by age and gender (Statistics Sweden). The results were considered statistically significant for $p$-values $\leq 0.05$. The statistical software used was $R$.

\section{Characteristics of the study population}

There were 3777 patients (67\% males) with open tibial fractures admitted to Swedish hospitals during the study period. Most fractures were located in the tibial shaft (60\%), $14 \%$ were located in the proximal part and $26 \%$ in the distal part of tibia. The mean age of the patients at admission was 47 (SD 20) years (males 42 [SD 20] and females 55 [SD 22]). The mean follow-up time was 6 (SD 3.8) years. Regarding surgical fixation methods, the most usual method was intramedullary nailing (32\%). Subsequent methods were combinations of external fixation and other (22\%), plating (9\%), external fixation only (8\%), closed reduction and cast (4\%), whereas $26 \%$ were fixated using miscellaneous methods. Causes of accident were in descending order motor vehicle accident (MVA, 43\%), fall from standing height (21\%), miscellaneous (19\%), fall from height (11\%) and unspecified falls (6\%).

\section{Results}

\section{Mortality rate}

Out of the population of 3777 patients, 425 individuals (212 males and 213 females) died during the study period. This resulted in a total mortality rate of $11 \%$ during the study period of 13 years. We excluded 11 male patients from the analysis because of incomplete data. The primary outcome, mortality in the population after 90 days was $2 \%$ ( 66 patients). Mortality from 90 days to 2 years was 3\% (109 patients). These numbers varied across age-groups, with the highest mortality being $11 \%$ after 2 years in patients aged 65 years and older (Table 1).

\section{Length of stay}

Mean LOS for primary admission ranged from 9 days (SD 15) in younger patients, to 10 days (SD 12) in middle-aged, and 14 days (SD 16) among the oldest.

\section{Causes of death}

Death was predominantly caused by cardiovascular disorders (180 deaths, 42\%), malignant neoplasms (79 deaths, $19 \%$ ) and by external causes (83 deaths, 20\%) (Fig. 1). A complete list of all causes of death is shown in the Appendix.

Among younger patients with an age of 15-39 years, the dominating cause of death was external (79\%). In the elderly ( $\geq 65$ ) external causes accounted for only $12 \%$ of the deaths. These proportions were similar in men and women. Death causes in different age groups are shown in Fig. 1. A transport accident (35 cases out of all 425 deaths) was the most common external cause. Less frequent were suicides $(n=12)$, poisoning $(n=10)$, falls $(n=8)$, homicides $(n=3)$, drowning $(n=2)$ and miscellaneous $(n=13)$.

We looked further at the subgroup of males aged 1560 years as males are specifically exposed to traumatic injuries [1, 2] (Fig. 2). Twelve individuals died within 3 months after they sustained their open tibial fracture, all because of the initial trauma or its complications. Six of them died on the day of the accident. All individuals had sustained severe high-energy trauma like motor cycle accidents, pedestrians hit by car, blast injury or a helicopter accident. Among those who died between 3 and 12 months $(n=10), 4$ deaths were caused by malignancies or co-morbidities and 6 deaths were due to external causes.

\section{Standard mortality ratio (SMR)}

Standard Mortality Ratio (SMR) and excess mortality in the different age groups was estimated at 0-90 days and 90 days-2 years (Tables 2, 3). There was an overall increased excess death rate, although in some groups there were very few individuals. SMR was higher for early mortality (Table 4).

Table 1 Mean length of stay and mortality rates in different age groups

\begin{tabular}{llll}
\hline Age [years] & $15-39$ & $40-64$ & $65-101$ \\
\hline Number of patients [n] & 1456 & 1564 & 744 \\
Number of deaths [n] & 28 & 111 & 286 \\
90-day mortality [n (\%)] & $6(0.4)$ & $11(0.7)$ & $49(6.5)$ \\
90-day to 2-year mortality [n (\%)] & $8(0.6)$ & $24(1.6)$ & $77(11.1)$ \\
Mortality during entire study period [\%] & 1.9 & 7.6 & 38.4 \\
\hline
\end{tabular}




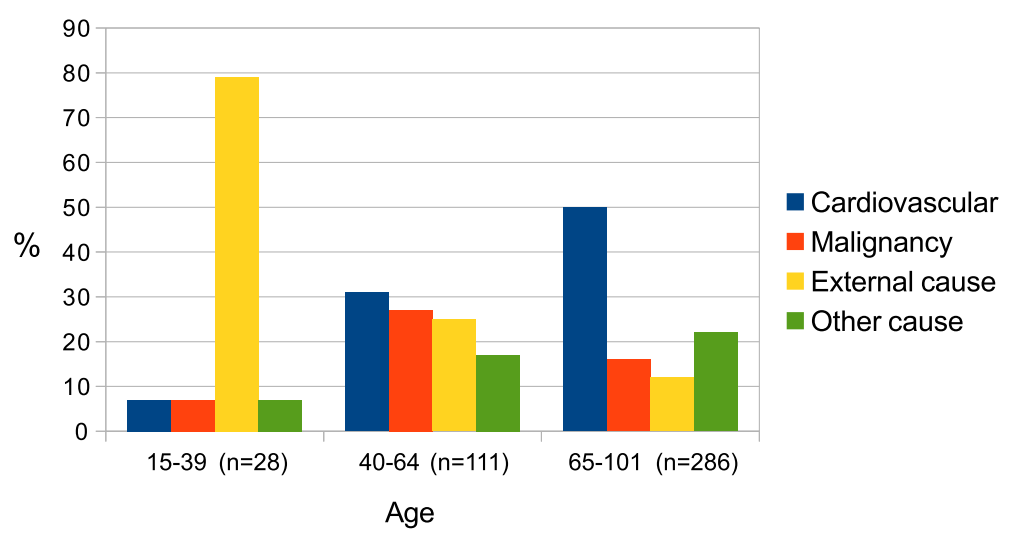

Fig. 1 Causes of death in different age groups

Logistic regression analysis revealed factors associated with death during the first 90 days. For early death, adjusted analysis showed that factors that elevated the risk for death were age 65 and above and limb amputation (Table 4). Cox regression analysis revealed risk factors for death from 90 days and beyond. For later death, the independent risk factors were age 40 and above, limb amputation, increasing length of stay and cause of accident. Fall from standing height was chosen as reference variable among causes of accidents, regarded as a low energy accident. Among later deaths, a fall from standing height was associated with a higher mortality (Table 5).

\section{Discussion}

In this nationwide study of all Swedish patients with open tibial fractures from 1998 to 2010 we found an increase in mortality compared to the general population.

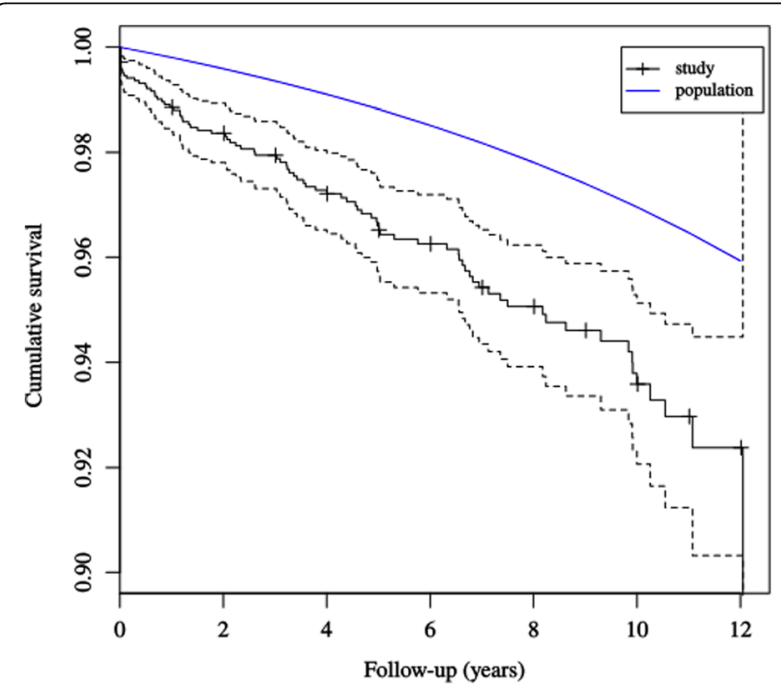

Fig. 2 Kaplan-Meier survival function with 95\% confidence interval for males aged 15-60 years compared to the general population of Sweden
Younger males seem to be a subgroup of patients prone to violent death and self-destructive behaviour.

\section{Mortality and SMR}

Overall mortality after 90 days was $2 \%$. This number is relatively low but pronouncedly higher than in the population, showed by an increased SMR. In fact, SMR was increased in all age groups, men and women, showing that the number of observed deaths exceeded the number of expected deaths in the population.

Connelly et al. conducted a study of 1474 patients with tibial fractures, closed as well as open, with a long-time follow-up of 12-22 years [15]. The mortality rate in patients over the age of 75 years was $42 \%$. In our study, total mortality during the study period of 13 years was 38\% among patients 65-101 years. These results are similar and also demographic data indicate a comparable population. In a small prospective series of 54 elderly patients ( $>65$ years) with tibial fractures the mortality rate was $11 \%$ after 6-months follow-up [12]. No statistical significant difference was found between open and closed fractures, in contrast to two other studies [13,14]. Clement et al. studied the outcome of 225 elderly patients with tibia fractures during a 9 year period and found a significantly higher mortality in patients with open fractures compared with patients with closed fractures (27\% vs $17 \%, p<0.001)$ [13]. They also found an increased SMR.

Elderly patients are known to have an increased mortality after injuries. This has been shown in hip fractures $[9,23,24]$, tibial fractures [12-14], open ankle fractures [25] and polytraumatized elderly patients [26, 27]. Our study supports this. Excess death rate was markedly increased in the elderly. A great focus in Swedish healthcare has been on hip fracture patients but in our opinion there is a need to prioritize all elderly patients. The impact of orthogeriatricians competency 
Table 2 Standard Mortality Ratio (SMR) and excess death rate until 90 days after injury

\begin{tabular}{llllllll}
\hline Age & Gender & Person-years & Deaths & SMR (95\%-CI) & Expected deaths & Excess deaths & Excess death rate \\
\hline $15-39$ & males & 286 & 5 & $28(10-62)$ & 0.178 & 4.822 & 1686 \\
& females & 79 & 2 & $80(13-264)$ & 0.025 & 1.98 & 2532 \\
\multirow{2}{*}{$40-64$} & males & 270 & 8 & $6.8(3.2-13)$ & 1.17 & 6.83 & 2527 \\
& females & 121 & 3 & $6.8(1.7-19)$ & 0.44 & 2.56 & 2119 \\
$65+$ & males & 75 & 25 & $13(9-19)$ & 1.88 & 23.12 & 30,824 \\
& females & 111 & 26 & $22.6(15-74)$ & 1.15 & 24.85 & 22,387 \\
\hline
\end{tabular}

SMR and excess death rate in different age and gender groups until 90 days after injury. $\mathrm{Cl}$ confidence interval

was studied in hip fracture patients [28]. In this study, they found that the number of orthogeriatricians hours per patient had an effect to reduce mortality regardless of time to surgery.

Causes of death were extracted from registry data. The reliability of the underlying cause of death was $77 \%$ according to a study from 1995 [29]. Younger age, malignancies and acute diseases were associated with higher reliability. In our study, death was predominantly caused by cardiovascular and respiratory disorders (180 deaths, accounting for 42\%), malignant neoplasms (79 deaths, 19\%) and by external causes (83 deaths, 20\%). External causes included accidents as well as self-destructive behaviour. As a comparison, in 2005 the dominating causes of death in the Swedish population were cardiovascular $(42 \%)$ and malignant neoplasms $(25 \%)$, whereas injuries and poisoning was the cause in only $5 \%$ of the cases [30]. In our study, external causes were overrepresented in all age groups and by far the most frequent cause among the youngest. This is in most cases explained by the accident itself as leading to death. Among elderly patients still cardiovascular disease was the most common cause of death. This sub-group of elderly patients sustain preferably low energy accidents that mostly will not lead directly to death. However, they are likely to have more co-morbidities that will be risk factors for cardiovascular causes of death.

Kaplan-Meier survival curves for younger males showed the increased mortality rate that was particularly increased during the first 2 years after the injury. Most individuals died relatively soon after their open fracture and apparently the cause of death was linked to the injury and its complications. Mortality rate continued to be increased even after the first months and we interpreted this as a subgroup of patients prone to dying of external causes. Causes of death often indicated violent accidents and self-destructive behaviour among these patients. This is consistent with work by Giannoudis et al., which demonstrated more problems with ongoing anxiety and depression in patient with Gustilo-type IIIB and IIIC fractures compared with the group of closed tibial fractures [6]. This fact raises the need for interventional measures such as psychosocial support after traumatic injuries and suicide prevention. Causes of accident were also analysed as independent risk factors for death. In our study, other causes of accident than a fall on the same plane were less associated with death. Our interpretation of this is that patients with co-morbidities and frailty are prone to sustain these injuries by low-energy accidents. Unprotected road-users as cyclists and motor bike drivers were shown to be at risk for fatal accidents in another study from France [31]. In our study the number of individuals in those sub-groups was small, and a statistical association may be difficult to show. Notably, in Sweden there is a national goal of no deaths in traffic including work on separate roads for cyclists.

Among the early deaths, a short LOS was associated with a higher risk of death. This illustrates the fact that many early deaths occur during the first few days after the accident.

Table 3 Standard Mortality Ratio (SMR) and excess death rate from 90 days until 2 years

\begin{tabular}{llllllll}
\hline Age & Gender & Person years & Deaths & SMR (95\%-Cl) & Expected deaths & Excess deaths & Excess death rate \\
\hline \multirow{2}{*}{ 15-39 } & males & 2220 & 6 & $4.8(2-10)$ & 1.25 & 4.75 & 237 \\
& females & 546 & 2 & $11.8(2-39)$ & 0.17 & 1.83 & 335 \\
$40-64$ & males & 270 & 8 & $6.8(3-13)$ & 1.17 & 6.83 & 2527 \\
& females & 845 & 5 & $1.6(0.6-3.6)$ & 3.09 & 1.91 & 227 \\
$65+$ & males & 525 & 25 & $1.9(1.3-2.8)$ & 13.17 & 11.83 & 2252 \\
& females & 777 & 55 & $6.8(5-9)$ & 8.05 & 46.95 & 604 \\
\hline
\end{tabular}

SMR and excess death rate in different age and gender groups from 90 days until 2 years after injury. $\mathrm{Cl}$ confidence interval 
Table 4 Risk factors for death within 90 days of the injury

\begin{tabular}{|c|c|c|c|c|c|c|}
\hline & \multicolumn{2}{|c|}{ Crude } & \multirow[b]{2}{*}{$p$} & \multicolumn{2}{|c|}{ Adjusted } & \multirow[b]{2}{*}{$p$} \\
\hline & $\mathrm{OR}$ & $95 \%-\mathrm{Cl}$ & & $\mathrm{OR}$ & $95 \%-\mathrm{Cl}$ & \\
\hline \multicolumn{7}{|l|}{ Gender } \\
\hline Males & 1.0 & ref & & 1.0 & ref & \\
\hline Females & 1.84 & $1.14-2.98$ & 0.01 & 0.84 & $0.48-1.46$ & 0.55 \\
\hline \multicolumn{7}{|l|}{ Age } \\
\hline $15-39$ & 1.0 & ref & & 1.0 & ref & \\
\hline $40-64$ & 1.54 & $0.61-4.20$ & 0.37 & 1.56 & $0.61-4.31$ & 0.36 \\
\hline $65-101$ & 23.3 & $11.2-56.6$ & $<0.005$ & 25.7 & $11.8-64.8$ & $<0.001$ \\
\hline \multicolumn{7}{|l|}{ Amputation } \\
\hline No & 1.0 & ref & & 1.0 & ref & \\
\hline Yes & 6.28 & $2.69-12.94$ & $<0.005$ & 4.8 & $1.9-11.1$ & $<0.001$ \\
\hline \multicolumn{7}{|l|}{ Length of stay } \\
\hline Unit per extra day & 1.00 & $0.97-1.02$ & 0.89 & 0.98 & $0.95-1.00$ & 0.07 \\
\hline \multicolumn{7}{|l|}{ Mechanism of injury } \\
\hline Fall from standing height $(n=20)$ & 1.0 & ref & & 1.0 & ref & \\
\hline Fall from height $(n=15)$ & 0.03 & $0.019-0.045$ & 0.76 & 1.05 & $0.51-2.13$ & 0.90 \\
\hline Unprotected road-users $(n=14)$ & 0.46 & $0.22-0.91$ & 0.026 & 0.83 & $0.38-1.76$ & 0.63 \\
\hline Car crash $(n=7)$ & 0.77 & $0.30-1.76$ & 0.56 & 1.65 & $0.61-4.06$ & 0.29 \\
\hline Other vehicles/objects $(n=5)$ & 0.42 & $0.14-1.05$ & 0.087 & 0.74 & $0.23-2.01$ & 0.58 \\
\hline Self-destructive injury $(n=2)$ & 0.75 & $0.12-2.63$ & 0.70 & 1.64 & $0.25-6.39$ & 0.53 \\
\hline Else $(n=6)$ & 0.69 & $0.25-1.64$ & 0.43 & 0.68 & $0.23-1.71$ & 0.44 \\
\hline
\end{tabular}

OR odds ratio, $\mathrm{Cl}$ confidence interval, ref reference value (adjusted for sex, age, amputation, length of stay (LOS) and mechanism of injury), $p p$-value, $n$ number of patients Logistic Regression Analysis and Cox Regression Analysis of Risk factors

Table 5 Risk factors for death from 90 days and beyond

\begin{tabular}{|c|c|c|c|c|c|c|}
\hline & \multicolumn{2}{|l|}{ Crude } & \multirow[b]{2}{*}{$p$} & \multicolumn{2}{|c|}{ Adjusted } & \multirow[b]{2}{*}{$p$} \\
\hline & $\mathrm{HR}$ & $95 \%-\mathrm{Cl}$ & & $\mathrm{HR}$ & $95 \%-\mathrm{Cl}$ & \\
\hline \multicolumn{7}{|l|}{ Gender } \\
\hline Men & 1.0 & ref & & 1.0 & ref & \\
\hline Women & 2.39 & $1.95-2.94$ & 0.005 & 0.94 & $0.75-1.17$ & 0.58 \\
\hline \multicolumn{7}{|l|}{ Age } \\
\hline $15-39$ & 1.0 & ref & & 1.0 & ref & \\
\hline $40-64$ & 4.28 & $2.72-6.74$ & $<0.005$ & 3.67 & $2.32-5.81$ & $<0.001$ \\
\hline $65-101$ & 31.1 & $20.3-47.8$ & $<0.005$ & 22.9 & $14.7-35.7$ & $<0.001$ \\
\hline \multicolumn{7}{|l|}{ Amputation } \\
\hline No & 1.0 & ref & & 1.0 & ref & \\
\hline Yes & 2.6 & $1.60-4.23$ & $<0.005$ & 1.79 & $1.08-2.95$ & 0.02 \\
\hline \multicolumn{7}{|l|}{ Length of stay } \\
\hline Unit per extra day & 1.011 & $1.009-1.014$ & $<0.005$ & 1.01 & $1.009-1.017$ & $<0.001$ \\
\hline \multicolumn{7}{|l|}{ Mechanism of injury } \\
\hline Fall from standing height $(n=66)$ & 1.0 & ref & & 1.0 & ref & \\
\hline Fall from height $(n=19)$ & 0.51 & $0.38-0.67$ & $<0.005$ & 0.59 & $0.44-0.78$ & $<0.001$ \\
\hline Unprotected road users $(n=8)$ & 0.21 & $0.15-0.28$ & $<0.005$ & 0.34 & $0.25-0.48$ & $<0.001$ \\
\hline Car crash $(n=2)$ & 0.21 & $0.13-0.36$ & $<0.005$ & 0.36 & $0.21-0.62$ & $<0.001$ \\
\hline Other vehicles/objects $(n=4)$ & 0.17 & $0.10-0.29$ & $<0.005$ & 0.30 & $0.18-0.51$ & $<0.001$ \\
\hline Self-destructive injury $(n=3)$ & 0.40 & $0.18-0.91$ & 0.029 & 1.20 & $0.53-2.75$ & 0.66 \\
\hline Else $(n=10)$ & 0.43 & $0.29-0.63$ & $<0.005$ & 0.48 & $0.32-0.72$ & $<0.001$ \\
\hline
\end{tabular}

HR hazard ratio, $\mathrm{Cl}$ confidence interval, ref reference value (adjusted for sex, age, amputation, length of stay (LOS) and mechanism of injury), $p p$-value, $n$ number of patients 
On the other hand, among later deaths, a longer LOS was associated with increased risk of death. A probable explanation could be that complications and co-morbidities lead to longer time in hospital. We had no knowledge of co-morbidities in this set-up which is a limitation of the study. In the Swedish patient register, primary diagnosis has a high validity but for co-morbidities data are more unsecure [16]. Similar conclusions were drawn in another study from the Unites States [32]. Considering this, we chose not to perform statistical analyses on co-morbidities.

Even though this is a nationwide study of the entire Swedish population of patients with open tibial fractures, the number of deaths was low. There were subgroups with very few patients. Statistical associations may be difficult to show.

This is a registry study with its advantages and disadvantages. Classifications like ASA (American Society of Anesthesiologists) class and ISS (Injury Severity Score), that would have been of interest in analysis, are not available from the register. Furthermore, there is no registration of the severity of the injury such as Gustilo classification. More severe injuries have higher risk for complications, as infection and amputation, and this might influence the risk of death [33-35].

\section{Conclusion}

Absolute mortality after open tibial fracture is relatively low, $2 \%$ after 90 days and 3\% after 2 years, although the risk of death is increased for all age and gender groups compared with the Swedish general population. External causes of death are over-represented and indicates a subgroup with a risky behaviour among younger males.

Patients aged 65 years and above have a pronouncedly enhanced excess death rate after open tibial fracture and should be treated with priority. Geriatric units and/or specialized geriatric care for elderly patients with traumatic injuries would be of value.

\section{Appendix}

Table 6 Death causes according to the European Shortlist in males and females in the different age groups

\begin{tabular}{|c|c|c|c|c|c|c|c|c|}
\hline \multirow[t]{3}{*}{ Death causes } & \multicolumn{2}{|l|}{ All } & \multicolumn{6}{|l|}{ Age } \\
\hline & \multirow[b]{2}{*}{ Male } & \multirow[b]{2}{*}{ Female } & \multicolumn{2}{|c|}{$15-39$} & \multicolumn{2}{|c|}{$40-64$} & \multicolumn{2}{|l|}{$65+$} \\
\hline & & & Male & Female & Male & Female & Male & Female \\
\hline Respiratory & 3 & 16 & & & & 2 & 3 & 14 \\
\hline \multicolumn{9}{|l|}{ Circulatory } \\
\hline Ischemic heart disease & 46 & 29 & 1 & & 17 & 1 & 28 & 28 \\
\hline Cerebrovascular disease & 9 & 25 & & & 3 & 2 & 6 & 23 \\
\hline Miscellaneous & 18 & 34 & 1 & & 7 & 2 & 10 & 32 \\
\hline Gastrointestinal & 2 & 8 & & & 1 & 1 & 1 & 7 \\
\hline Mental disorders & 9 & 13 & 1 & & 1 & 2 & 7 & 11 \\
\hline Malignant neoplasms & 46 & 33 & 2 & & 20 & 10 & 24 & 23 \\
\hline Endocrine disorders & 8 & 4 & & 1 & 2 & & 6 & 3 \\
\hline Musculoskeletal & 1 & 1 & & & 1 & & & 1 \\
\hline Genitourinary & & 3 & & & & & & 3 \\
\hline Diseases of the nervous system & & 8 & & & & 2 & & 6 \\
\hline Unknown & 7 & 9 & & & 5 & & 2 & 9 \\
\hline Miscellaneous & 4 & 6 & & & 2 & 2 & 2 & 4 \\
\hline \multicolumn{9}{|l|}{ External causes } \\
\hline Transport accident & 28 & 7 & 7 & & 9 & 2 & 12 & 5 \\
\hline Fall & 4 & 4 & 1 & & 1 & & 2 & 4 \\
\hline Poisoning & 6 & 4 & 4 & & 1 & 4 & 1 & \\
\hline Suicide & 8 & 4 & 6 & 1 & 1 & 2 & 1 & 1 \\
\hline Homicide & 2 & 1 & 1 & 1 & 1 & & & \\
\hline Drowning & 2 & & 1 & & 1 & & & \\
\hline Miscellaneous & 9 & 4 & & & 6 & & 2 & 5 \\
\hline Total & \multicolumn{2}{|c|}{425} & \multicolumn{2}{|l|}{28} & \multicolumn{2}{|c|}{111} & \multicolumn{2}{|c|}{286} \\
\hline
\end{tabular}




\section{Abbreviations}

ICD: International classification of diseases; LOS: Length of hospital stay; SMR: Standard mortality ratio; SNHDR: Swedish national hospital discharge register

\section{Acknowledgements}

We thank Dr. Stefan Israelsson Tampe for his support with the statistical analysis and Dr. Jonathan Forsberg for valuable help with the manuscript.

\section{Availability of data and materials}

The datasets supporting the conclusions of this article are available from the the author if needed.

\section{Authors contributions}

UT and K-ÅJ designed the study. UT analyzed the data and wrote the manuscript. LWW and RJW were major contributors in writing the manuscript. All authors read and approved the final manuscript.

\section{Ethics approval and consent to participate}

The study was approved by The Regional Ethical Review Board of Stockholm North (2011/1280-32). This study is based on national registries held by the National Board of Health and Welfare in Sweden. Identification data are not known by the researchers and consent to participation is not applicable.

\section{Consent for publication}

Not applicable.

\section{Competing interests}

The authors declare that they have no competing interests

\section{Publisher's Note}

Springer Nature remains neutral with regard to jurisdictional claims in published maps and institutional affiliations.

\section{Received: 17 February 2018 Accepted: 16 July 2018}

\section{Published online: 25 July 2018}

\section{References}

1. Court-Brown CM, Bugler KE, Clement ND, Duckworth AD, McQueen MM The epidemiology of open fractures in adults. A 15-year review. Injury. 2012; 43(6):891-7. https://doi.org/10.1016/j.injury.2011.12.007.

2. Tampe U, Weiss RJ, Stark B, Sommar P, Al Dabbagh Z, Jansson K-Å. Lower extremity soft tissue reconstruction and amputation rates in patients with open tibial fractures in Sweden during 1998-2010. BMC Surg. 2014;14(1):80 https://doi.org/10.1186/1471-2482-14-80

3. Weiss RJ, Montgomery SM, Ehlin A, Al Dabbagh Z, Stark A, Jansson K-A. Decreasing incidence of tibial shaft fractures between 1998 and 2004: information based on 10,627 Swedish inpatients. Acta Orthop. 2008;79(4): 526-33. https://doi.org/10.1080/17453670710015535.

4. Olesen UK, Pedersen NJ, Eckardt $\mathrm{H}$, et al. The cost of infection in severe open tibial fractures treated with a free flap. Int Orthop. 2017;41(5):1049-55. https://doi.org/10.1007/s00264-016-3337-6.

5. Chung KC, Saddawi-Konefka D, Haase SC, Kaul G. A cost-utility analysis of amputation versus salvage for Gustilo type IIIB and IIIC open tibial fractures. Plast Reconstr Surg. 2009;124(6):1965-73. https://doi.org/10.1097/PRS. Ob013e3181bcf156.

6. Giannoudis PV, Harwood PJ, Kontakis G, et al. Long-term quality of life in trauma patients following the full spectrum of tibial injury (fasciotomy, closed fracture, grade IIIB/IIIC open fracture and amputation). Injury. 2009; 40(2):213-9. https://doi.org/10.1016/j.injury.2008.05.024.

7. Antonova $E$, Le TK, Burge R, Mershon J. Tibia shaft fractures: costly burden of nonunions. BMC Musculoskelet Disord. 2013;14(1):1. https://doi.org/10. 1186/1471-2474-14-42.

8. Bosse MJ, MacKenzie EJ, Kellam JF, et al. An analysis of outcomes of reconstruction or amputation after leg-threatening injuries. N Engl J Med. 2002:347(24):1924-31. https://doi.org/10.1056/NEJMoa012604.

9. Harris AM, Althausen PL, Kellam J, Bosse MJ, Castillo R. Complications following limb-threatening lower extremity trauma. J Orthop Trauma. 2009; 23(1):1-6. https://doi.org/10.1097/BOT.0b013e31818e43dd.
10. Parvizi J, Ereth MH, Lewallen DG. Thirty-day mortality following hip arthroplasty for acute fracture. J Bone Joint Surg Am. 2004;86-A(9):1983-8.

11. Karampampa K, Ahlbom A, Michaëlsson K, Andersson T, Drefahl S, Modig K. Declining incidence trends for hip fractures have not been accompanied by improvements in lifetime risk or post-fracture survival a nationwide study of the Swedish population 60years and older. Bone. 2015;78:55-61. https://doi.org/10.1016/j.bone.2015.04.032.

12. Cox G, Jones S, Nikolaou VS, Kontakis G, Giannoudis PV. Elderly tibial shaft fractures: open fractures are not associated with increased mortality rates. Injury. 2010;41(6):620-3. https://doi.org/10.1016/j.injury. 2009.12.013.

13. Clement ND, Beauchamp NJF, Duckworth AD, McQueen MM, Court-Brown CM. The outcome of tibial diaphyseal fractures in the elderly. Bone Joint J. 2013;95 B(9):1255-62. https://doi.org/10.1302/0301-620X.95B9.

14. Adler A, Boylan MR, Rosenberg C, et al. In-hospital mortality following open and closed long bone fracture: a comparative study. Surg Technol Int. 2015:26:337-42. http://www.ncbi.nlm.nih.gov/pubmed/26055029. Accessed 25 June 2015

15. Connelly CL, Bucknall V, Jenkins PJ, Court-Brown CM, McQueen MM, Biant LC. Outcome at 12 to 22 years of 1502 tibial shaft fractures. Bone Jt J. 2014; 96B(10):1370-7. https://doi.org/10.1302/0301-620X.96B10.32914.

16. Ludvigsson JF, Andersson E, Ekbom A, et al. External review and validation of the Swedish national inpatient register. BMC Public Health. 2011;11(1):450. https://doi.org/10.1186/1471-2458-11-450

17. Johansson LA. Dödsorsaksstatistik-Historik, produktionsmetoder och tillförlitlighet. 2010. http://www.socialstyrelsen.se/publikationer2010/2010-4-33. Accessed 4 Jul 2017

18. Socialstyrelsen. Statistik om dödsorsaker. http://www.socialstyrelsen.se/ statistik/statistikefteramne/dodsorsaker. Accessed 29 April 2017.

19. eurostat. European Shortlist for Causes of Death. 2012. http://ec.europa. eu/eurostat/ramon/nomenclatures/index.cfm?TargetUrl=LST_NOM_ DTL\&StrNom $=$ COD 2012\&StrLanguageCode $=E N \& I n t P c K e y=$ \&StrLayoutCode=HIERARCHIC. Accessed 29 April 2017.

20. De MEC, Gomes R, Falcão MTC, Schwarz E, Das NACM, Santos W. Gender inequalities in external cause mortality in Brazil, 2010. Cien Saude Colet. 2015;20(3):779-88. https://doi.org/10.1590/141381232015203.11172014

21. Koskenvuo M, Kaprio J, Lönnqvist J, Sarna S. Social factors and the gender difference in mortality. Soc Sci Med. 1986;23(6):605-9. http://www.ncbi.nlm. nih.gov/pubmed/3764510

22. Statistiska Centralbyrån. Statistikdatabasen. http://www.statistikdatabasen. scb.se/pxweb/sv/ssd/?rxid=a5ba7c29-0532-4ae0-904e-cd1ca20a4a4f. Accessed 4 Jul 2017.

23. von Friesendorff M, Besjakov J, Åkesson K. Long-term survival and fracture risk after hip fracture: a 22-year follow-up in women. J Bone Miner Res. 2008;23(11):1832-41. https://doi.org/10.1359/jbmr.080606

24. von Friesendorff M, McGuigan FE, Wizert A, et al. Hip fracture, mortality risk, and cause of death over two decades. Osteoporos Int. 2016;27(10): 2945-53. https://doi.org/10.1007/s00198-016-3616-5.

25. Toole WP, Elliott M, Hankins D, Rosenbaum C, Harris A, Perkins C. Are low-energy open ankle fractures in the elderly the new geriatric hip fracture? J Foot Ankle Surg. 2015;54(2):203-6. https://doi.org/10.1053/j. jfas.2014.10.015.

26. Clement ND, Tennant C, Muwanga C. Polytrauma in the elderly: predictors of the cause and time of death. Scand J Trauma Resusc Emerg Med. 2010;18(1):26. https://doi.org/10.1186/1757-7241-18-26.

27. Abdelfattah A, Core MD, Cannada LK, Watson JT. Geriatric high-energy Polytrauma with orthopedic injuries: clinical predictors of mortality. Geriatr Orthop Surg Rehabil. 2014;5(4):173-7. https://doi.org/10.1177/ 2151458514548578

28. Neuburger J, Currie C, Wakeman R, et al. Increased orthogeriatrician involvement in hip fracture care and its impact on mortality in England. Age Ageing. 2016:1-7. https://doi.org/10.1093/ageing/afw201.

29. Johansson LA, Björkenstam C, Westerling R. Unexplained differences between hospital and mortality data indicated mistakes in death certification: an investigation of 1,094 deaths in Sweden during 1995. J Clin Epidemiol. 2009;62(11):1202-9. https://doi.org/10.1016/j.jclinepi. 2009.01.010.

30. Socialstyrelsen Epidemiologiskt Centrum. Dödsorsaker 2005. 2007. http:// www.socialstyrelsen.se/Lists/Artikelkatalog/Attachments/9324/2007-42-15 20074215_rev.pdf. Accessed 29 April 2017. 
31. Bouaoun L, Haddak MM, Amoros E. Road crash fatality rates in France: a comparison of road user types, taking account of travel practices. Accid Anal Prev. 2015;75:217-25. https://doi.org/10.1016/j.aap.2014.10.025.

32. Samuel AM, Lukasiewicz AM, Webb ML, et al. ICD-9 diagnosis codes have poor sensitivity for identification of preexisting comorbidities in traumatic fracture patients. J Trauma Acute Care Surg. 2015;79(4):622-30. https://doi. org/10.1097/TA.0000000000000805.

33. Chua W, Murphy D, Siow W, Kagda F, Thambiah J. Epidemiological analysis of outcomes in 323 open tibial diaphyseal fractures: a nine-year experience. Singap Med J. 2012;53(6):385-9. http://www.ncbi.nlm.nih.gov/pubmed/ 22711037

34. Enninghorst N, McDougall D, Hunt JJ, Balogh ZJ. Open tibia fractures: timely debridement leaves injury severity as the only determinant of poor outcome. J Trauma. 2011;70(2):352-6-7. https://doi.org/10.1097/TA.0b013e31820b4285.

35. Khatod M, Botte MJ, Hoyt DB, Meyer RS, Smith JM, Akeson WH. Outcomes in open tibia fractures: relationship between delay in treatment and infection. J Trauma. 2003;55(5):949-54. https://doi.org/10.1097/01.TA 0000092685.80435.63.

Ready to submit your research? Choose BMC and benefit from:

- fast, convenient online submission

- thorough peer review by experienced researchers in your field

- rapid publication on acceptance

- support for research data, including large and complex data types

- gold Open Access which fosters wider collaboration and increased citations

- maximum visibility for your research: over $100 \mathrm{M}$ website views per year

At $\mathrm{BMC}$, research is always in progress.

Learn more biomedcentral.com/submissions 